\title{
Resenha do livro Democrazia: l'invenzione degli antichi e gli usi dei moderni
}

Luís Falcão

\section{Luís Falcão}

Doutor em Ciência Política pelo IESP/UERJ. Professor da Universidade Federal Fluminense.

ORCID: https://orcid.org/0000-0003-3785-626X

A dificuldade inicial que o leitor enfrenta ao percorrer as páginas de Democrazia: l'invenzione degli antichi e gli usi dei moderni reside na classificação propriamente da obra. Estudiosos da história do pensamento político talvez se sintam ainda mais aflitos com o livro. Não se trata de uma abordagem da democracia a partir de vertentes largamente utilizadas, seja por filósofos, historiadores, cientistas políticos ou filólogos, mas de um conjugado preciso e absolutamente inovador de perscrutar o tema. Se, por um lado, é certamente um reducionismo entendê-lo como uma abordagem meramente lexical da transformação do uso do vocábulo nos diversos idiomas ocidentais, por outro, seria igualmente equivocado alocá-lo em uma história das ideias, em um contextualismo linguístico ou uma análise do discurso, para citar os métodos mais em voga recentemente. A obra destaca criticamente a questão da premência ocidental da reflexão e atividade política em sua forma melhor aceita contemporaneamente, a democracia.

Tendo em vista uma tal situação, este estudo retoma o problema da tradição e da herança do léxico político. A história da democracia no mundo moderno corresponde à recriação contínua de algo do passado, a partir do passado, mas dentro de esquemas temporais distintos e, às vezes, divergentes. (LIMA, 2019, p. x)

Essa recriação que nos fala o autor se refere à sua própria penetrante atenção a respeito de como a relação entre a palavra e a coisa depende, antes, da situação na qual o observador impõe sentido à palavra e à coisa. Isso significa que estamos diante de um trabalho cujo ponto vital, do qual a originalidade não pode se deixar de acentuar, reside na apreensão da democracia tendo por base o universo político que circunda cada etapa dessa apreensão. E o percurso é longuíssimo. Desde a retomada das obras antigas no século XIII que traziam a palavra grega democracia até o seu espraiamento pela Ásia e África contemporâneas, reconstrói-se o percurso dessa recriação, toda vez que se reivindica algo democrático remete-se à origem, recriandoos, ambos, esse algo e a origem. Seja um clérigo medieval, seja um economista indiano ainda atuante, ambos, ao se referirem à democracia, simultaneamente, observam o mundo que os cercam e reconstroem o conceito, pela reinterpretação do passado ou pela abstração do presente e quiçá pela prospecção do futuro. O que importa é que essas duas dimensões não podem ser dissociadas, e é disso que nos alerta o livro.

O capítulo inicial, o mais teórico da obra, tem o cuidado de apresentar as condições nas quais é possível a reconstrução da história da democracia, com o aviso, nem sempre seguido por esse tipo de pesquisa, de que não há outra forma de 
se contar uma história senão do presente. O engano de se procurar no passado os valores democráticos do presente é uma armadilha na qual Butti de Lima não cai. Não está em jogo o uso político de democracia, nos diversos momentos da modernidade, mas a transmissão de uma palavra grega para um universo político completamente distinto, embora reivindicador do mesmo conceito. Não se trata, portanto, de uma comparação de uma, digamos, democracia dos antigos com a dos modernos, mas da dificuldade lexical, e portanto conceitual, de reivindicação da palavra cujo sentido não

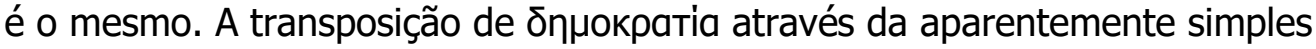
transliteração para democratia abarcou uma força que o latim e os idiomas vernáculos não puderam nem podem absorver ou reproduzir. Por isso, compreende-se a importância de suas diferentes usos, não apenas em contextos diferentes, mas sobretudo em sequenciamento cronológico em suas principais aplicações, o que não significa que os regimes teorizados tenham precedência sobre os existentes ou viceversa. Mas que o uso por uma importante autoridade antiga conduziu o emprego de democracia eivado por ele.

Foi Aristóteles quem pontuou os argumentos mais contundentes da antiguidade a favor do regime democrático, ainda que isso não signifique, absolutamente, que o filósofo tenha sido seu defensor. O que interessa a Butti de Lima é justamente o modo como o estagirita foi lido e apropriado pelo fato de ter sido redescoberto no ocidente já como uma importantíssima autoridade, da qual a escolástica é a primeira testemunha. Não vai aqui somente um estudo da recepção do filósofo nos diferentes contextos, mas a disputa sobre o que seja a democracia tendo como ponto fundamental de análise a posição do estagirita.

Assim, deve o leitor manter-se alerta sobre essa entrada, a pesquisa poderia se debruçar sobre outras fontes lexicais gregas que sobreviveram ao tempo, como aristocracia, anarquia e tirania. Mas, além de isso ser objeto de outro estudo, a centralidade da democracia na história ocidental impõe todas as suas particularidades, sobretudo, se for observado o contexto pós-segunda guerra. Compreendido desse modo, o livro torna-se ainda mais imprescindível porquanto se atente ao recentíssimo debate sobre as fragilidades da democracia, seu arrefecimento em diversos lugares e sua cada vez mais explícita crítica. Ainda que não tenha sido esse o objetivo inicial do autor, os diferentes modos pelos quais a democracia foi usada, criticada e defendida são, na última década mais do que em grande parte do século $X X$, vitais para se compreender os fundamentos da civilização ocidental e, sobretudo, seus pontos fracos. O livro, portanto, se propõe a uma simultânea análise sobre a "criação" e a "expropriação" da democracia originária dos antigos gregos, que pode tanto ser lido como uma ocorrência particular quanto universal.

O capítulo dois apresenta uma fortíssima inflexão na história da democracia que está além da criação e expropriação de suas origens. Maquiavel, afirma o autor, foi o primeiro, desde Aristóteles, a argumentar sobre as características positivas do povo e, o que é singularmente interessante, a presença do filósofo grego no pensamento do florentino não é nada evidente. Aliás, sequer o vocabulário específico - democracia - é mobilizado por ele. Em parte, naturalmente, isso pode ser explicado pela difusão binária da Política, a partir das transliterações de Moerbeke ou pelas adaptações latinas da versão que Leonardo Bruni fez da obra. Mas essa parte explicativa não justifica a constância e sabedoria do povo em relação aos aristocratas e governantes em Maquiavel. Pelo contrário, é a despeito do uso aristotélico dos séculos anteriores, nos quais havia premência da monarquia ou da aristocracia, que Maquiavel 
recoloca o povo como ator político central e avança, assim, em um modo inteiramente inovador de se pensar a política.

Uma preocupação que percorre a obra, pela via do jusnaturalismo, reside nas interpretações de cunho antropológico, a partir dos diversos expansionismos europeus. Em que medida as populações não ocidentais se enquadrariam na democracia? A resposta a essa pergunta permite que se jogue tal regime para a natureza humana: se os ameríndios estivessem em estado de natureza, Hobbes deveria estar equivocado quanto à guerra de todos para com todos. Lafitau e Charlevoix, missionários na américa, comparam os costumes dos ameríndios aos gregos antigos. Nesse contexto, poder-se-iam destacar as premissas do que se chamaria filosofia da história cujo fundamento no progresso humano é legitimado pelas comparações entre lugares e tempos diferentes. Afinal, os ameríndios vivem em situação análoga aos gregos ou mesmo a civilizações anteriores. Provam, esses povos, que há, na natureza, traços eminentemente democráticos.

Ao tratar das revoluções americana e francesa, o livro estabelece a conexão com os termos da democracia originária de linguagem contratualista com a condição sui generis da colônia inglesa, cujo principal representante até inícios do século seguinte seria James Wilson. A contribuição pioneira do debate americano do período reside, porém, na noção de que a democracia, em si mesma, possui vantagens e inconvenientes que lhes são próprios e, com isso, a questão central passa a ser como manter os primeiros e anular os segundos. Uma consequência lógica dessa aparentemente singela inovação reflete, possivelmente pela primeira vez na história, um problema de aplicação instantânea de um regime ainda em fase especulativa, que se inicia com os critérios de legitimidade dos poderes de maiorias e minorias. Ou seja, o que se tornaria matéria de debate durante o século XIX, na fundação americana já era uma questão prática. Uma solução comum, da qual Madison é o ponto alto, foi a de separar democracia de república, contrariando Montesquieu e outros, a tal ponto de se alocar na primeira os inconvenientes da tirania, anarquia, facção e violência, e nas vantagens de seus princípios, a legitimidade do poder, a participação, a liberdade e o autogoverno.

A partir da revolução francesa, é o campo semântico democrático que passa a ser empregado nas mais diversas esferas da vida comum, inovação essa, inclusive, em relação ao caso americano. Porém, a análise dos discursos das diversas etapas revolucionárias não deixa dúvidas, contrariamente ao senso comum, da enorme resistência que a democracia enfrentou, seja com a teoria da representação de Sieyès ou com sua inferioridade frente ao despotismo de Marat, mas com exceções de SaintJust e Robespierre, com as devidas revivescências para uma nova democracia. Esse movimento do texto contribui para desfazer um sentimento comum de que a revolução francesa, de lados mais ou menos populares, foi a grande manifestação ocidental de criação do que se chama democracia atualmente. Não se trata de revisionismo, mas de reconhecer a completa desconexão entre a democracia dos "antigos" e sua versão absolutamente inovadora.

Dois temas pouco usuais nos estudos sobre democracia devem ser destacados: 1) como o governo dos mais pobres e, por isso, o único verdadeiramente atento às questões sociais; 2) como a realização do comunismo. A dimensão classista dessas duas vertentes se conflui na ideia de uma realização democrática vindoura, numa época em que a igualdade e a liberdade sejam o pleno desfrute humano. Malgrado todas as críticas sofridas, mais atuais do que nunca, a ação política se 
configura como o termo central da plenitude das potencialidades humanas, cuja libertação se faz pelo ataque aos termos que mais caracterizam a modernidade.

Ao percurso escolhido pelo autor poder-se-ia, evidentemente, incorporar um enorme conjunto de outras contribuições para os usos modernos da democracia dos antigos, a exemplo de John Fortescue (2002, p. 8-9), para quem a unidade das virtudes antigas é sumarizada por Leonardo Bruni, em absoluto acordo com "o Filósofo", Aristóteles. Seu regimen politicum se baseia no governo das leis e não dos homens e se sustenta na crítica de Tomás de Aquino à oligarquia e à democracia, sob os critérios qualitativos aristotélicos, que diferem, respectivamente, a aristocracia, "que é o governo dos poucos bons, chamados de optimates, e o governo dos muitos bons, chamado de politia" (FORTESCUE, 2002, p. 135). O interessante de Fortescue dentro da empreitada de Butti de Lima é que ele possui uma contribuição singular dentro da transmissão binária de Aristóteles (a de Moerbeke e a de Bruni), já que autoriza o critério aristotélico (Política 1273a38-40) do melhor governo pela virtude a partir de Bruni, e mantém a tipologia das formas de governo do vocabulário de Moerbeke, via Tomás. Escrevendo em vernáculo, ainda na Inglaterra, Thomas Smith vai além e mobiliza, além das transliterações, os próprios caracteres gregos para as formas de governo, sempre, baseado na Política: a basileia vira "king"; o tiranus, um "tyrant"; a aristocracia, a "Remp. optimatum"; a oligarquia, o "Paucorum potestatem" (SMITH, 1982, p. 50). Mas a "common wealth" é chamada pelo "nome genérico de politeia", e se divide em reta e corrompida (SMITH, 1982, p. 50-51). A esse quadro, Smith remete, como mostra Butti de Lima em outros autores, aos exemplos atenienses e romanos para a democracia e o governo misto, contrastados aos de seu tempo. Sua Inglaterra é desse segundo tipo, cuja parte democrática não prepondera sobre as demais.

É claro que exemplos assim poderiam ser multiplicados e que uma obra com tamanha amplitude está sempre aberta a se aprofundar nos detalhes e isso, de fato, é um mérito fundamental do texto. Porque, ao invés das ausências, como as de Fortescue e Smith, deporem contra a obra, ao contrário, é apenas porque o trabalho foi cautamente escrito que podemos encontrar em Fostescue e Smith as chaves da "criação" e "expropriação" grega em textos não trabalhados pelo livro. Nesse sentido, o livro transpassa em muito os autores e textos nele tratados e amplia a capacidade do estudioso para situações e teorias não exploradas.

Ainda na Introdução, retomado no último capítulo, Butti de Lima discutiu o problema que Evans-Pritchard reconheceu ao empregar palavras ocidentais para povos não ocidentais pela falta de uma linguagem neutra do antropólogo e, assim, acabou por ter que reconhecer os limites, mas a inevitabilidade, do uso de "democracia" para esses povos. No último capítulo do segundo volume de Civilização e Cultura, Luís Câmara Cascudo se dedica a temas mais caracteristicamente políticos e afirma a premência de um único chefe para todos os agrupamentos humanos, depois, debruçase sobre os conselhos de anciãos para, na sequência, dizer que "ao lado da figura do chefe, anterior, o Conselho é a primeira assembleia consultiva e depois deliberadora [...] Esses Conselhos foram as origens remotas e legítimas das assembleias legislativas" (CASCUDO, 1973, p. 404). Os exemplos mobilizados, de todos os continentes, podem ser lidos como um conjunto de provas históricas do terceiro livro da Política, ao responder o que é uma cidade, seu caráter natural, mas também aos livros subsequentes, onde as três formas de governo são aqui evidenciadas: o chefe, o conselho e a assembleia. Mas Câmara Cascudo não se reporta à democracia, sua tipologia das instituições políticas está subsumida na reflexão aristotélica, sequer citada: um evidente exemplo de "criação" e "expropriação" dos gregos sem mencioná- 
los como fontes teóricas, apenas antropológicas. "Com a aparição do chefe político rei ou tirano -, aparecem as formações aristocráticas e, assim, as democráticas, as quais, deveríamos concluir, renascem agora em uma realidade estável, diferente da realidade democrática anterior" (LIMA, 2019, p. 145). Agora, não é o vocabulário político grego que se impõe ao mundo, mas a humanidade dos gregos que se mostra evidente porquanto não se distinguem dos outros povos (cf. cap. 10).

A implícita confirmação da tese aristotélica - um, poucos e muitos transbordou do próprio Aristóteles. E o fato de o livro resenhado não tratar de Câmara Cascudo apenas nos auxilia na leitura do escritor brasileiro, mas podemos ver, no capítulo 7, com a análise sobre a historiografia do século XIX o significado dos mesmos temas: religião como fundante da sociedade, costumes locais e a "estrutura gentilícia como base da vida pré-política" (LIMA, 2019, p. 246).

Aristóteles não apenas fixou o vocabulário formal da democracia em âmbito constitucional, as diversas apropriações levaram também à reflexão sobre uma moralidade democrática que pouco, ou nada, deve à forma de governo. Esses dois modos de se encarar a democracia, na modernidade, se diferenciariam a ponto de, dizse nos EUA, "se o fascismo ocorresse nos Estados Unidos, seria chamado de democracia" (adup. LIMA, 2019, p. xv). Além disso, se há um denominador convergente dos quais diversos usos da democracia por parte dos modernos é justamente a enorme dificuldade que existe em falar dessa forma de governo nas condições de Estados nacionais formados, territórios e populações enormes, plena economia de mercado e direitos individuais. A democracia, lembra-nos sempre Paulo Butti de Lima, é uma constante referência aos antigos, a partir dos quais os modernos usam e se apropriam.

(Recebido para publicação em julho de 2020)

(Reapresentado em agosto de 2020)

(Aprovado para publicação em outubro de 2020)

\section{Cite esta resenha}

FALCÃO, Luís, 2020. Resenha do livro Democrazia: l'invenzione degli antichi e gli usi dei moderni.

Revista Estudos Políticos: a publicação semestral do Laboratório de Estudos Hum(e)anos (UFF). Rio de Janeiro, Vol.11 |N.1, pp.119-124, outubro de 2020.

\section{Bibliografia}

1. CASCUDO, Luís Câmara, 1973. Civilização e cultura. Brasília: MEC.

2. FORTESCUE, John, 2002. On the laws and governance of England (1478-1471). Edited by Shelley Lockwood. Cambridge: Cambridge University Press.

3. LIMA, Paulo Butti de 2019. Democrazia: I'invenzione degli antichi e gli usi dei moderni. Milano: Mondadori.

4. SMITH, Thomas, 1982. De republica anglorum (1583). Edited by Mary Dewar. Cambridge: Cambridge Universit 